\title{
An unusual cause of haemorrhage in the subthalamic nucleus of luys: A post-mortem study with 7.0 tesla magnetic resonance imaging correlates
}

\author{
Jacques De Reuck, Florent Auger, Nicolas Durieux, Vincent Deramecourt, Claude-Alain Maurage, Regis Bordet \\ Université Lille Nord de France, France
}

Received: January 27, 2017

Accepted: March 19, 2017

Online Published: March 21, 2017

DOI: $10.5430 /$ ijdi.v4n2p20

URL: https://doi.org/10.5430/ijdi.v4n2p20

\begin{abstract}
The present case report is the first one of an isolated haemorrhage in the subthalamic nucleus of a patient with an isolated central nervous system relapse of systemic non-Hodgkin lymphoma. The neuropathological findings and 7.0-tesla magnetic resonance imaging correlates are presented.
\end{abstract}

Key Words: Haemorrhage of the subthalamic nucleus, Non-Hodgkin lymphoma, Neuropathology, T2*-weighted 7.0-tesla MRI sequence

\section{INTRODUCTION}

A cerebrovascular accident, especially a haemorrhage is the most common lesion affecting the subthalamic nucleus of Luys. Less usual causes are a metastasis, a demyelinising process, a head injury, a tuberculoma or as a complication of stereotactic interventions. ${ }^{[1-3]}$

We present the case history and the neuropathological findings in a patient with as incidental finding at post-mortem examination a haemorrhage in the right subthalamic nucleus of Luys of unusual origin. Also the post-mortem 7.0-tesla magnetic resonance imaging (MRI) are described.

\section{Case history}

A 61-year-old man was admitted in January 2009 for fever of unknown origin. Three hepatic lesions together with abdominal adenopathies were observed on computed tomography. Blood analysis revealed signs of inflammation. The liver tests were normal. No improvement of the fever was obtained with antibiotics and steroids. Liver biopsies, performed in February 2009, revealed lymphomas possibly of the Hodgkin type. Remission was obtained by chemotherapy in August 2009. In October 2010 the patient developed generalized seizures. The examination did not show focal neurological signs. On MRI of the brain, however, three infiltrating lesions were observed: one in the right cerebellar hemisphere, one in the right parietal subcortical region and one in the upper brain stem. No haemorrhages were detected at that time. Two stereotactic cerebral biopsies were not able to reveal any tumour invasion. The patient deceased five months later.

\section{Material and Methods}

Post-mortem examination was obtained by written informed consent from the nearest family. The brain tissue samples were first used for diagnosis and afterward integrated in the Lille Neuro-Bank, dependant from the Lille University and co-federated by the "Centre des Resources Biologiques",

*Correspondence: Jacques De Reuck; Email: dereuck.j@ gmail.com; Address: Leopold II laan 96, 9000 Ghent, Belgium. 
acting as institutional review board.

In addition to the gross examination of the brain, samples for microscopically examination were stained with haematoxylin eosin, luxol fast blue and Perls Prussian blue.

Three coronal sections of a cerebral hemisphere were submitted to T2 and T2* MRI: a frontal one at the level of the head of the caudate nucleus, a central one at the level of the mammillary body and one at the level of the parietal and occipital lobes. In addition one horizontal section of brainstem and cerebellar hemisphere was also examined. A 7.0-tesla MRI Bruker BioSpin SA with an issuer-receiver cylinder coil of $72 \mathrm{~mm}$ inner diameter (Ettlingen, Germany) was used, according to a previous described method. ${ }^{[4]}$

\section{Results}

The general autopsy showed bronchopneumonia and many necrotic and old haemorrhagic lesions in the liver. Not tumour cells were detected Gross examination of the brain showed a haemorrhage restricted to the right subthalamic nucleus of Luys. No other lesions were observed on naked eye examination (see Figure 1A). On T2 and T2* weighted MRI images a diffuse hypo-intensity of the basal ganglia was observed in addition to the subthalamic bleed (see Figure $1 \mathrm{~B}-1 \mathrm{C})$ ).
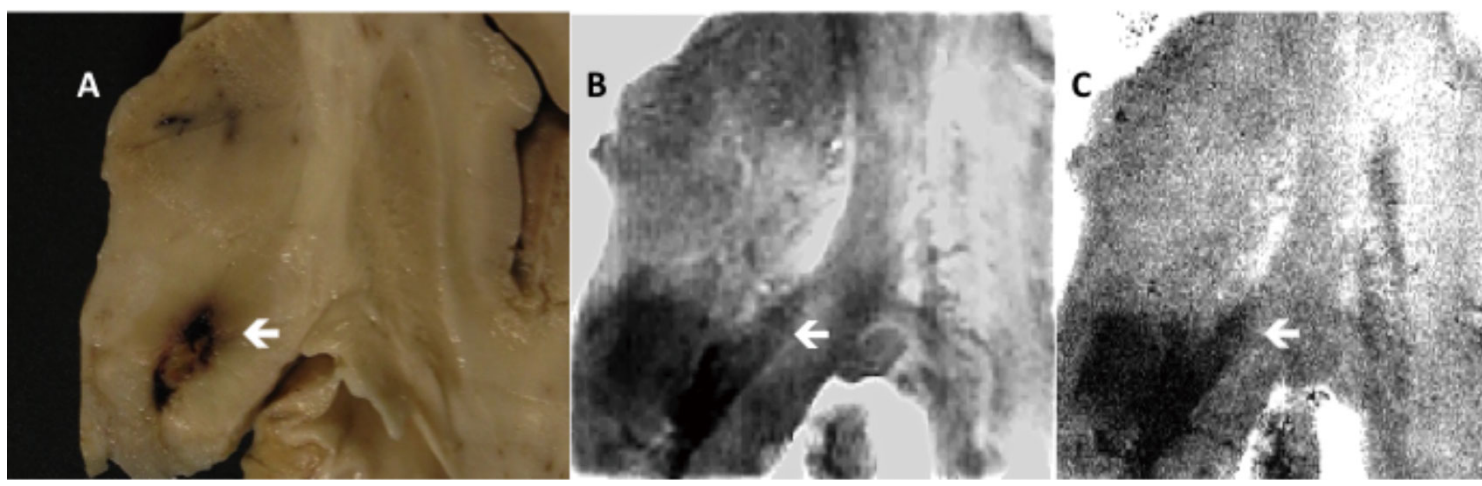

Figure 1. Coronal section of the right cerebral hemisphere. A: the gross examination only shows the haemorrhage in the subthalamic nucleus (arrow); B-C: on the T2 and T2* MRI sequences not only the haemorrhage is shown (arrows) but also a diffuse hypo-intensity in the basal ganglia

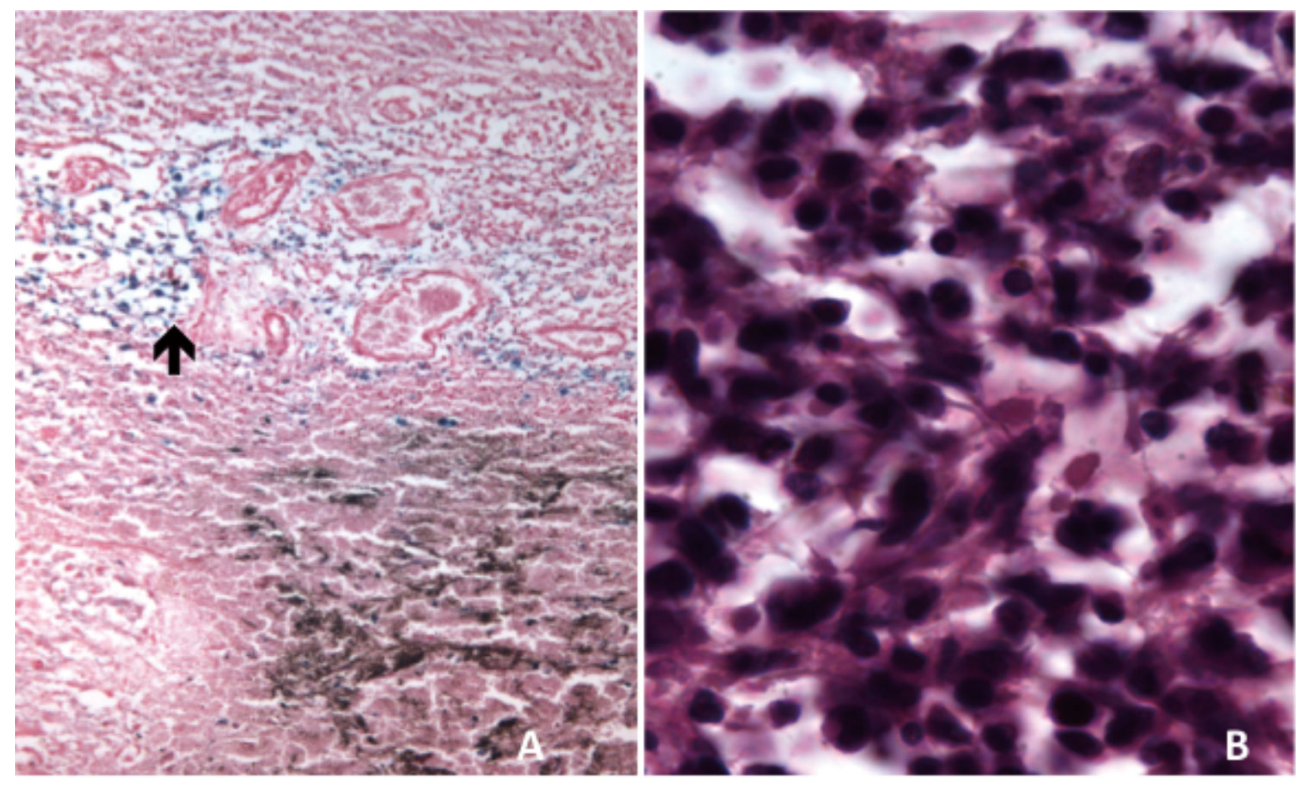

Figure 2. Microscopic examination of the lesions. A: haemosiderin deposits are demonstrated in the subthalamic nucleus (arrow) with the Perls Prussian blue stain; B: high-magnification view of the non-Hodgkin lymphoma with the Haematoxylin-Eosin stain 
On microscopic examination siderophages and residual haemosiderin deposits were observed in the subthalamic nucleus of Luys (see Figure 2A). Polymorphic infiltrates of large lymphoid cells with many mitoses were observed in the right basal ganglia and subcortical structures, also invading the upper brainstem. There was also tumoural infiltration of the blood vessel walls. Although some large cells resembled to Sternberg cells the tumour was considered as a non-Hodgkin lymphoma (see Figure 2B).

\section{Discussion}

The overall incidence of intracranial haemorrhage among adult patients with haematological malignancy is $2.8 \%$. It is more common among patients with central nervous system involvement by a lymphoma with a cortical predilection site of $83 \% .{ }^{[5]}$ However, isolated central nervous relapse involving the brain parenchyma is a rare complication of systemic non-Hodgkin lymphoma. ${ }^{[6]}$

The present case report is the first one of a unique haemorrhage in the subthalamic nucleus related to isolated central nervous system relapse of systemic non-Hodgkin lymphoma.

\section{CONFlicts OF INTEREST DISClosure}

The authors have declared no conflicts of interest.

\section{REFERENCES}

[1] Ceusters W, De Bleecker J, De Reuck J. Hemiballism. Clinicopathological conference. Acta Neurol Belg. 1987; 87: 229-233. PMid:3673495

[2] Provenzala JM, Glass JP. MRI in hemiballismus due to subthalamic nucleus hemorrhage: an unusual complication of liver transplantation. Neuroradiology. 1996; 38 Suppl 1: S75-77. https: //doi.org/10.1007/BF02278125

[3] Pabaney A, Ali R, Lewitt PA, et al. Successful management of hemorrhage-associated hemiballismus after subthalamic nucleus deep brain stimulation wth pallidal stimulation: a case report. World Neurosurg. 2015: 84.

[4] De Reuck J, Auger F, Cordonnier C, et al. Comparison of 7.0-T
$\mathrm{T} 2 *$-magnetic resonance imaging of cerebral bleeds in post-mortem brain sections of Alzheimer patients with their neuropathological correlates. Cerebrovasc Dis. 2011; 31: 511-517. PMid:21422755 https://doi.org/10.1159/000324391

[5] Chen CY, Tai $\mathrm{CH}$, Cheng A, et al. Intracranial hemorrhage in adult patients with hematological malignancies. BMC Med. 2012. https ://doi.org/10.1186/1741-7015-10-97

[6] Doolittle ND, Abrey LE, Shenkier TH, et al. Brain parenchyma involvement as isolated central nervous system relapse of systematic non-Hodgkin lymphoma: an International Primary CNS Lymphoma Collaborate Group report. Blood. 2008; 111: 1085 1095. PMid:17962515 https://doi.org/10.1182/blood-200 7-07-101402 